\title{
Desalination in Qatar: Present Status and Future Prospects
}

\author{
Hammadur Rahman and Syed Javaid Zaidi* \\ Center for Advanced Materials Qatar University, Qatar
}

Submission: November 26, 2018; Published: December 07, 2018

*Corresponding author: Syed Javaid Zaidi, Center for Advanced Materials Qatar University, Qatar

\begin{abstract}
The world depends on water to sustain life and cater to development. Gulf region is among the most arid environments of the world with no natural water resource, minimum to no rainfall. Complete water requirement is fulfilled by seawater desalination. With increasing urbanization, population growth and increase in standard of living increases the requirement of clean water dramatically. In this paper review the current status and shift of trend in seawater desalination will be discussed about Qatar with reference to the Gulf countries. Qatar is blessed with unprecedented natural gas and oil reserves and the least amount of water available per capita and highest per capita CO2 emission. Water desalination and clean water has been identified as one of the major challenges in Qatar National Vison 2030. As Qatar economy is based on seawater desalination to overcome the water shortages, reduce the carbon footprint, preparation for 2022 FIFA world cup while achieving the goal of vision 2030 Qatar is shifting from the energy-intensive convention thermal desalination process to a much cleaner greener membrane process for seawater desalination
\end{abstract}

Keywords: Thermal desalination; Reverse osmosis; Shift of trend in desalination; Seawater desalination, Qatar water problem, Qatar vison 2030 , Qatar

\section{Introduction}

The most pervasive problem afflicting almost one third of the world's 7 billion population is inadequate access to clean water. The rate of water consumption will continue to rise in the coming decades. Having access to clean water is a global problem even in countries, which are rich in natural water resources. With current unstable price of crude oil, the cost of clean water is also on the rise. Clean water is much more important than all other natural resources. water is essential element to sustain life and cater advancement of a country. Oceans are the most abundant resource of water as earth's surface covering almost $75 \%$ area. Out of which $97 \%$ is unfit for drinking due to high salinity. In the remaining $3 \%$ almost $70 \%$ is frozen in ice glaciers, the remaining $28 \%$ of the tiny $3 \%$ is fresh deep underground water which is not accessible or not feasible in some cases. All the fresh water aquifers, lakes, rivers make up $2 \%$ of tiny $3 \%$. Water is the commodity that governs the life of people and sustainability, advancement that can be achieved by a community, this is proved by a fact that all major civilization was developed within $100 \mathrm{~km}$ of large water bodies. Majority of those still face water scarcity today in some form depending upon the topographical location, population and environment. In the Asian countries it is mainly due to the misuse of water resources, improper recycling of wastewater, government polices etc. Where as in the Gulf cooperation council (GCC) consisting of six countries "Qatar, Oman, Kuwait, Bahrain, Saudi, UAE" it is due to the fact that this region is an arid desert land with little to no natural clean water. The whole Gulf region has little to no underground water resources. There are few water resources that concentrated in Oman and south cost of Saudia [1]. Gulf region has an average rainfall of $75 \mathrm{ppm}$ with an evaporation rate of over $3000 \mathrm{ppm}$ which offset the requirement. The salinity of seawater of the Arabian Peninsula is significantly higher than other parts of the world with total dissolved solids (TDS) ranging from 40000 to50000ppm [2]. Due to this alarming level of water scarcity the governments of GCC countries with rich reserve of fosil fuels have turned toward desalination of seawater to fulfil their water needs [3]. Most of the water requirement in the gulf region, almost $99 \%$, is fulfilled by sea water desalination. The Gulf region accounts for more than $60 \%$ of the global desalination capacity. The desalination in gulf region is mainly based upon thermal and reverse osmosis technologies.

The ease of access of saline water through Arabian sea for desalination of sea water prompted the gulf countries setting up water desalination industries along the coast of the Arabian gulf. As a resulted all the desalination plants are located in close proximity to each other, which has increased water salinity of the region due to brine disposal and lead to various environmental problems. The location of desalination plants in the Arabian Peninsula are depicted in (Figure 1)[4]. 


\section{Civil Engineering Research Journal}

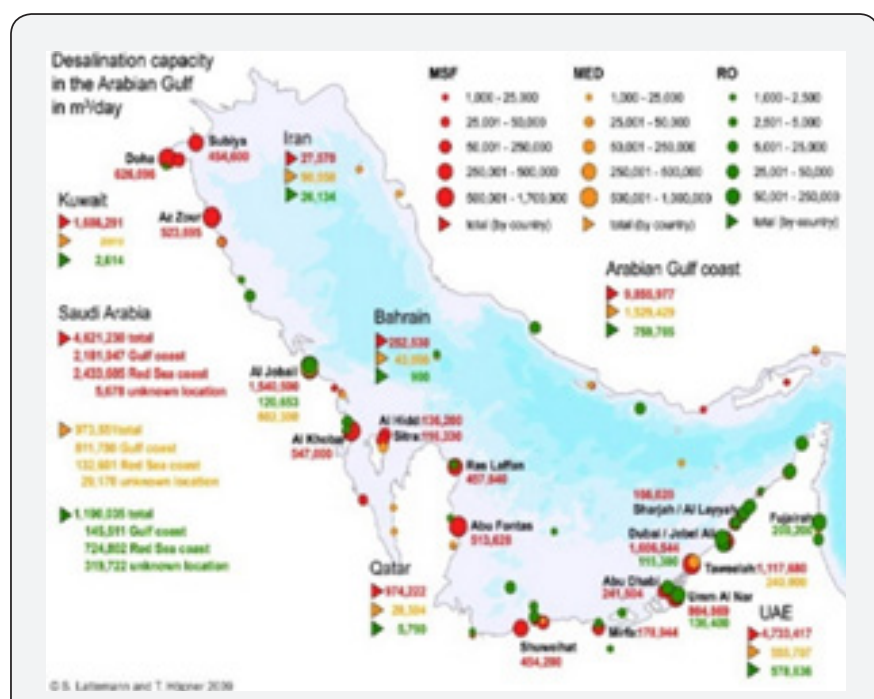

Figure 1: Desalination plants in the Arabian gulf [4].

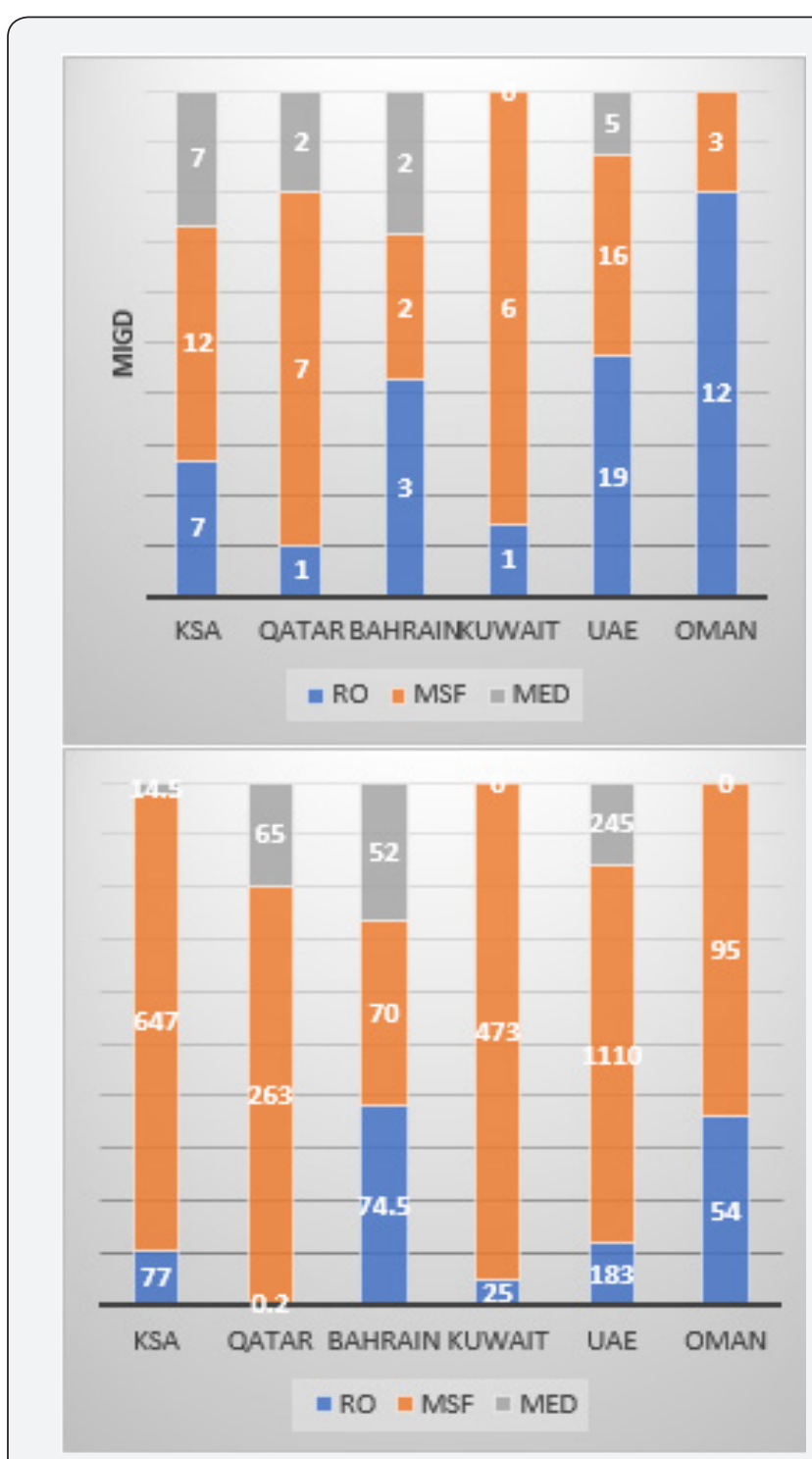

Figure 2: (a) Number of Desalination Plants in the Gulf (b) Desalination capacity of existing plants.
Desalination of seawater was first introduced in the year 1950s in Kuwait followed by Qatar in 1955. In the early years of seawater desalination, the plants setup and installed were completely based on the thermal desalination process until 1970 [5] (Figure 2). shows the total number of major desalination plants in GCC and their overall production capacity. Qatar population in the early 2000s was around 0.5 million and by the end of 2012 the population increased more than three times reaching 2 million and has crossed 2.6 million by June of 2018 and is predicted to reach 4 million by the year 2030 . This exponential increase in population increases the requirement for clean water for domestic and industrial use. Moreover, the massive infrastructure developments in Qatar and higher standards of living are increasing the demands of clean water. Also, environmental concerns of $\mathrm{CO}_{2}$ emissions as a result of use of hydrocarbon resources in the thermal desalination process and their cost effectiveness make the thermal desalination process not an ideal one. Taking these factors into account the GCC governments are shifting to reverse osmosis seawater desalination [6-8].

This paper reviews the past present and future of Qatar's sea water desalination technology. The two important commercial processes, which are used to desalinate seawater for water supply in Qatar are based on thermal process, such as multi stage flash (MSF) distillation and multi-effect distillation (MED), and membrane-based process such as reverse osmosis technology.

\section{Technologies}

Desalination basically means separation of the salts from sea water to get two streams one with high concentration of salts and other pure water fit for domestic and industrial use. To achieve the separation of sea water into two stream some form of energy is required for separation. A variety of technologies are available to achieve the separation depending upon the type of feed water intake and salinity of water like MSF, MED, RO. The most successful desalination processes used commercially in the GCC region are multi stage flash distillation and reverse osmosis. Initially MSF was used due the availability of low-cost fuel and high salinity of feed water of the region. Recently reverse osmosis is replacing the MSF due to lower cost of production, simple design, environment friendly, ease of maintenance and modular nature. Both the technologies are presently used in Qatar and are explained below.

\section{Multi stage Flash Distillation}

The first flash evaporation system was built in 1957 in Kuwait with a capacity of 1 MIGD followed by Qatar in1960 with a capacity 1.5 MIGD in 1962. First plant of other GCC countries are summarised in Table 1. The multi-stage flash distillation desalination system involves phase change. It works by the phenomenon of boiling sea water under pressure lower than the atmospheric pressure. The steam from the boiled water is pure which is condensed to get pure drinking water. This boiling of seawater under $100{ }^{\circ} \mathrm{C}$ is known as flashing technique used 
in multi stage flash distillation columns [2,9]. The MSF process is made economical by using it simultaneously with power generation plants, the MSF process consist of heat input, heat recovery and heat rejection units. Sea water is heated under low-pressure brine heater in which steam is externally supplied. seawater flows on the tube side of the heat exchanger. The heated sea water then flows into the flash evaporator section containing multiple stages with temperature ranging from 90$120^{\circ} \mathrm{C}$ depending upon the feed water quality and type of pretreatment done. Operating plant at $120{ }^{\circ} \mathrm{C}$ increases efficiency but it also increases corrosion and chances of scale formation. At each stage the vacuum is increased making more pure water evaporate at lower temperature. The water evaporated comes in contact with cold condenser tubes, which condenses and forms pure water. At each stage the concentration of brine is increased as the water is being vaporized. At the end concentrated brine is discharged from the process.

Table 1: MSF plant start date in GCC [5].

\begin{tabular}{|c|c|c|c|}
\hline Country & Date & Plant name & Capacity MIGD \\
\hline Qatar & 1962 & Ras Abu Abood & 1.5 \\
\hline Oman & 1976 & Al Ghabra Massira & 5 \\
\hline Kuwait & 1960 & Shuwaika E1 \& E2 & 2 \\
\hline Bahrain & 1975 & Sitgra a \& b & 5 \\
\hline UAE & 1977 & Abu Dhabi vapour plant & 15 \\
\hline KSA & 1967 & Al Dhaba & 0.8 \\
\hline
\end{tabular}

\section{Reverse Osmosis}

Reverse osmosis desalination is a physical process which work on the movement of water from area of high level of concentration to an area with low concentration. It is the reverse of the osmosis process. This movement happens through a special type of barrier called semi preamble membrane, which allows the flow of water and restricts the salts. Under the influence of a pressure higher than the osmotic pressure to the side with higher salinity. In this process there is no need for phase separation or heating. The energy required in this process is only used to power the high-pressure centrifugal pumps. The amount of pressure required depends on the salinity of the feed water, temperature. Major component of reverse osmosis sea water desalination process are as follows

\section{Pre-Treatment}

\section{High pressure pumps}

3. Membrane separation

4. Post treatment.

Raw sea water is initially filtered travelling through screens to remove large debris. Further the sea water is taken in to multimedia gravity filter media which has slice, sand and granite as media. This helps to remove the suspended solid in the sea water intake. In Qatar dissolved air floatation is used to increase contact time by dispersion of bubbles to enhances removal of algae, oil, other polymerics substances of low density that float and cannot be separated by sedimentation. Finally, the sea water is drawn into cartridge filter which remove particles that are larger than 10 microns. Pretreatment is needed to eliminate the undesirable constituents in sea water which will lead to membrane fouling. This is required to clear the feed water of possible foulant or scalant causing minerals and make it suitable for membrane filtration. The type of pre-treatment used directly depends upon the quality feed water intake.

High pressure pumps are used to pump the pre-treated seawater up to the required pressure by reverse osmosis membrane to achieve the desired separation of feed water into pure water and concentrated brine streams. For this application, centrifugal pumps are used, which operate in the range of 5080 bar. The membrane modules are arranged in spiral wound configuration. As the process operates at ambient temperature and the material of construction of membrane is non-corrosive. the scale formation is close to zero in reverse osmosis process [10]. In the last section after the membrane filtration units, water goes for post treatment. To normalize water for domestic use by stabilizing the alkalinity by adding calcium hydroxide with $30-40 \mathrm{ppm}$ chlorine is added to safeguard water from microorganism during storage and transportation. Finally, water flows through decarbonization system to maintain the $\mathrm{PH}$ of water [2,9,11,12] (Table 2).

Table 2: First RO plants in Gulf [5].

\begin{tabular}{|c|c|}
\hline Country & Date \\
\hline Qatar & 1982 \\
\hline Oman & 1982 \\
\hline Kuwait & 1987 \\
\hline Bahrain & 1984 \\
\hline UAE & 1977 \\
\hline KSA & 1968 \\
\hline
\end{tabular}

\section{Shift of Trend in Desalination}

The size of thermal plants is quite large with its main material of construction as steel which is prone to corrosion under heating and low-pressure conditions continuously. Scales are formed as $\mathrm{Mg}$ and $\mathrm{Ca}$ salts and forms layer on the inner walls of the heat exchangers, which reduces plant efficiency significantly. The MSF plant consumes a huge amount of energy with total consumed equivalent mechanical energy of $20 \mathrm{kwh} /$ $\mathrm{m}^{3}$ of desalinated water. The Average estimated cost of $1 \mathrm{kwh}$ of mechanical work estimated to 0.11 dollars, then the energy cost to produce $1 \mathrm{~m}^{3}$ of desalinated water is equal to 2.2 dollars for MSF system. Which is excepted to increase as the fuel prices are increasing globally.

Apart from the cost, large size of the plant, troubleshooting problems, plant operation shutdown, cleaning and maintenance, harmful $\mathrm{CO}_{2}$ emissions, high temperature of concentrated brine discharged into the sea, disrupting the marine eco system, all of them make the plant costlier $[13,14]$. Due to these factors 


\section{Civil Engineering Research Journal}

most of the new plants commissioned or planned for sea water desalination in the recent years in Qatar and the Gulf region are based on reverse osmosis process technology as the total energy equivalent required in terms of mechanical energy is equal to $5 \mathrm{kwh} / \mathrm{m}^{3}$. Cost of which is equal to 0.55 dollar per $\mathrm{m}^{3}$ (estimated $1 \mathrm{kwh}$ work equals 0.11 dollar) of desalinated water, which is significantly less as compared to MSF plant and Reverse osmosis plant pre-2000 of similar desalinated water capacity [15]. The reason behind such huge price gap is SWRO doesn't require heating and condensing, the only main energy consumption is by the pump and over the years due to the development of highly efficient membranes that can operate longer duration before a need of cleaning and replacement, the centrifugal pumps used today use significantly less energy while having higher output then before and use of energy recovery devices which are attached to the outlet of concentrated brine stream which is coming from the membrane unit. The brine only losses the applied pressure very slightly (1-4 bar of the applied pressure from the high-pressure pump). this high-pressure brine stream is directed to a turbine and which rotates to produce power used in powering the pre-treatment process (Figure 3) [6].

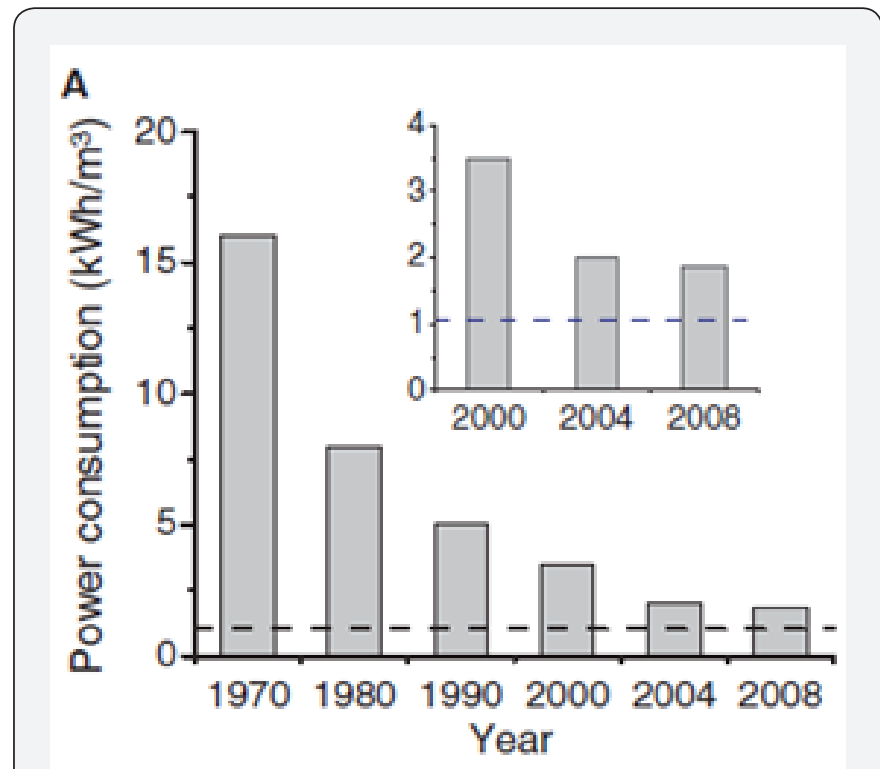

Figure 3: (a) change in power consumption Ro stage of SWRO plants from 1970 to 2008.the dashed lines is theoretical minimum energy required for desalination at $50 \%$ recovery (values excluding energy required for intake, pre-treatment and post treatment).

The size of a typical RO plant is almost 70\% percent smaller than a typical MSF plant of same capacity. The reverse osmosis plant has a modular design in the form of horizontal or vertical stack of membrane called as RO trains attached in series or parallel which are generally made up of a material which is non corrosive to sea water due to which it requires very less shutdown and maintenance operation can be done while the plant is online, the only energy consumed in RO is by the pump with all the above factors reducing the cost of setting up and operation of plant has turned QATAR and other GCC countries government to shift to reverse osmosis plant for its new projects [5].

\section{Qatar Past Present Future}

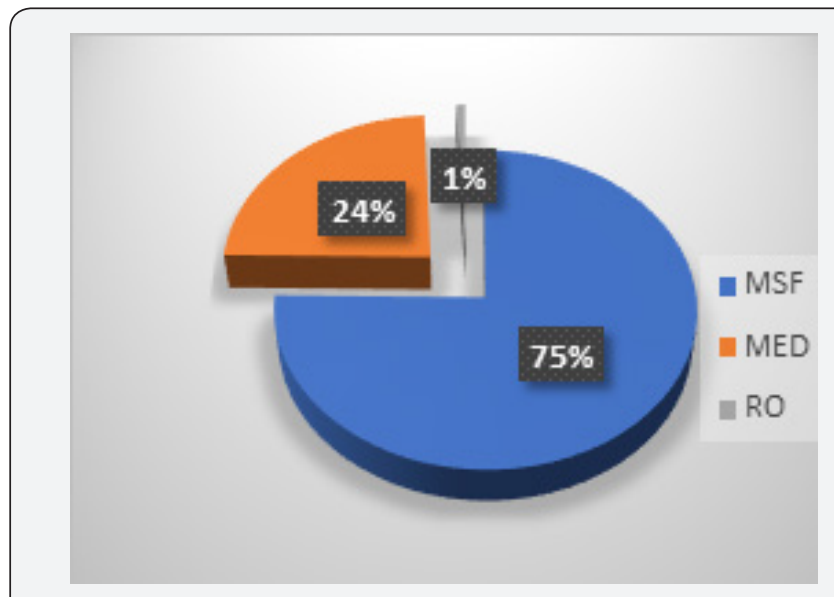

Figure 4: Overall capacity of Qatar sea water desalination up to 2010 .

The first sea water desalination plant in Qatar was established in the year 1953 based on submerged tube process with a capacity of $682 \mathrm{~m}^{3} /$ day. The second plant was set up in the year 1962 at Ras abu Abood based upon the commercially successful multi stage flash distillation process (MSF) with a capacity of 1.5 MIGD. The third plant was established in 1977 at Ras Abu Fantas which was also based upon MSF. The fourth plant was built at Abu Samra in the year 1982 based on a new reverse osmosis technology with a capacity of $909 \mathrm{~m}^{3}$ per day (Figure 4). The fifth major desalination plant was set up in the year 2016 at Ras Abu Fantas based upon the reverse osmosis sea water desalination. The sixth and the latest plant is set up at Umm Al Houl with a capacity of 136MIGD, out if which 60MIGD is achieved using reverse osmosis process and the remaining 76MIGD is achieved by a hybrid MSF co power generation plant. Commissioning of all the desalination plant in Qatar along with the capacity and technology used are summarized in Table 3 and Figure 5 shows the overall percent share of each desalination technology used in Qatar.

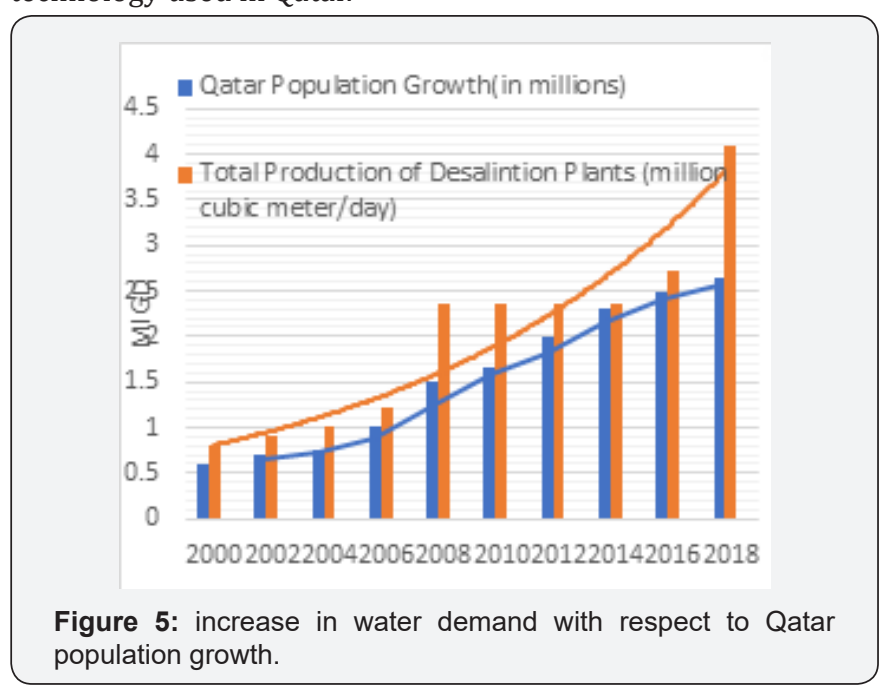




\section{Civil Engineering Research Journal}

Table 3: Desalinisation plants of Qatar [5].

\begin{tabular}{|c|c|c|c|}
\hline Plant & Capacity (MIGD) & Technology & Commissioning year \\
\hline Ras Abu Fantas & 55 & MSF & MSF \\
\hline Ras Abu Fantas b & 33 & MSF & $2003-2004$ \\
\hline Ras Laffana & 40 & MSF & $2006-2008$ \\
\hline Ras Laffan-b Qatar power & 60 & RO & $1994)$ \\
\hline Abu Samra & 0.2 & MSF & 1993 \\
\hline Qaeedat al Shamal & 0.2 & MSF & 2010 \\
\hline Ras Abu Fantas A1 & 45 & MSF & 2008 \\
\hline Ras Abu Fantas B2 & 30 & MED & $2010-2011$ \\
\hline Ras Qertas & 63 & MED & 1997 \\
\hline Dukan & 2 & RO & 2016 \\
\hline Ras Abu Fantas A3 & 36 & RO & $2016-2017$ \\
\hline Umm al houl & 60 & MSF & \\
\hline Total & 76 & & \\
\hline
\end{tabular}

As reported by Qatar statistics authority the population of Qatar as of June 2018 was 2.6 million. This compared to 1.15 million population in 2008, which is more than 2 times in the last 10 years and this compared to 0.5 million population in the year 2000 which has almost increased by 4 times the last 18 years which is represented in Figure 5.

The prime goal of Qatar vison 2030 is to have a sustainable development in the present to have a better tomorrow for future generations. Which can be achieved by reducing the use of hydrocarbon by shifting to energy efficient processes with less $\mathrm{CO}_{2}$ emissions. while having minimal impact on the environment and marine eco-system. One of the major grand challenge of Qatar vison 2030 is producing and providing safe drinking water while keeping the water production under the guidelines of vison 2030. Qatar is an arid country with limited to no underground water with severe lack in rainfall of only $82 \mathrm{~mm} /$ year and evaporation rate of $2000 \mathrm{~mm} /$ year. As a result of which Qatar falls below the international water poverty line of $1000 \mathrm{~m}^{3}$ per capita per year.

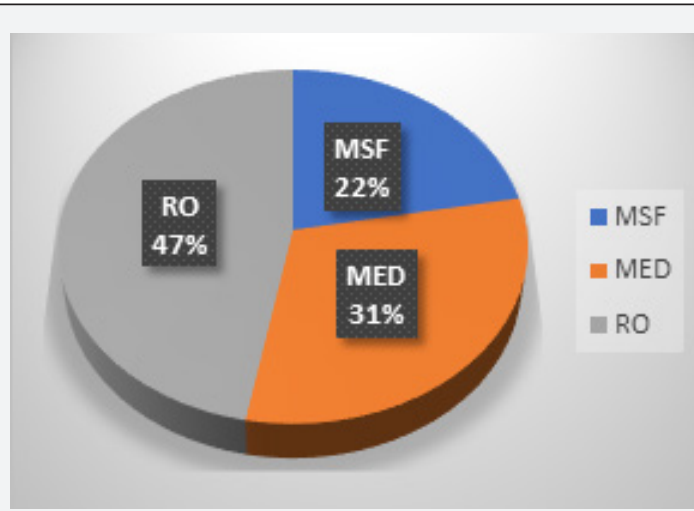

Figure 6: Expected Qatar sweater desalination 2016-2022

The fast-economic growth, rapid agricultural growth, social development, current fast track licensing and tax free set up for new upcoming industries leading to alluring job opportunities along with a tax-free salary, boom in local farming as an outbreak of ongoing illegal siege on the country. Due all these reasons the Qatar population is increasing exponentially and is expected to increase up to 4.4 million by 2030 . This increases the water and energy demand and puts pressure on country's water and energy resources due to which the nonconventional production of desalinated water is to be expanded to support the demand for the current development and be prepared for future requirement due to which two new plant are set up. One in "Rs Abu Fantas 3" with a capacity of 36MIGD and the second in "Umm Al Houl" plant with a total capacity of 136MIGD out of which 60MIGD is based on reverse osmosis sea water desalination and other 73MIGD is based on thermal plant integrated with power generation technology. With the new RO plant commissioned the overall share of RO has increased drastically as shown in Figure 6. Both of these plants are cost effective as they use way less energy, have zero $\mathrm{CO} 2$ emissions, with easy maintenances, which aligns with the guidelines in achieving of vision 2030 successfully and beyond. [1,9,15,16,17] (Figure 6).

\section{A. Future prospects}

Currently all the GCC countries are in a process to modify their existing plant or completely replace them by Reverse osmosis processes plant. More and more funds are allotted to research and development of sea water desalination technology as the whole region is dependent of desalinated water. As a result of which sea water desalination technology is getting better by various new emerging technologies which can complement, improve the current MSF and RO process, while other emerging technology can completely replace the existing technologies and reduce the cost of production further Figure 7 depicts the overall increases in the number of upcoming major desalination plants in GCC and their overall production capacity.

B. Solar energy 


\section{Civil Engineering Research Journal}

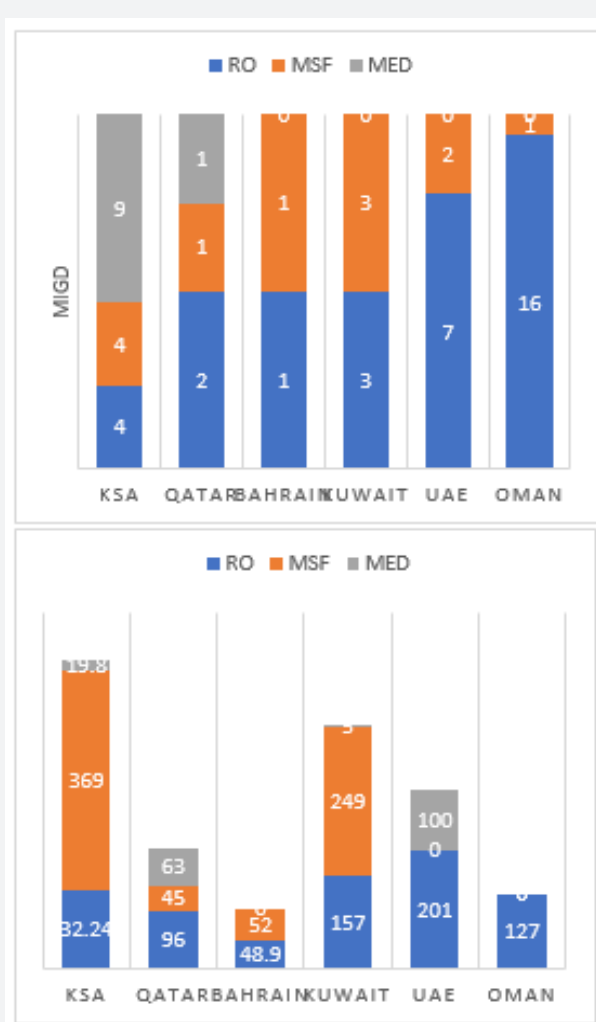

Figure 7: (A) Desalination station under construction (b) excepted gulf desalination capacity of plant under construction.

Solar distillation in the form of solar still is an ancient but novel method to produce potable water and through modern technology, its various losses can be minimized to enhance its utility. More R\&D on the design of solar stills would provide a range of systems which could be utilized depending upon the situation. The concept of the solar pond, solar collector and the photovoltaic cell can be integrated along with solar stills to produce the best result. [15,18-20].

\section{Hybrid system}

With the expansion in the R\&D around the globe, the world is turning toward the hybrid systems to produce the solution for the problems faced currently in present desalination process. Desalination is be benefited with hybrid systems which use technologies from different disciplines to produce fresh water. Solar PV cell along with wind energy, a combination of nanofiltration and ultrafiltration for pre-treatment, using electro dialysis and reverse osmosis as complementary methods, a plant using forward osmosis integrated with nanofiltration and triple hybrid power-MSF-SWRO are examples which provide an edge over simple systems used in the past [21-23].

\section{Feed water pre-treatment}

Desalination is an emerging field in the twenty-first century as the boiler technology was at the beginning of the twentieth century. Process modification and various techniques are to be invented so that the system is loss minimized. MSF, MED and pretreatment of saline water through the various membrane can further simplify the entire process. There is a need for research in this area which can improve plant utilization.

\section{a) Forward osmosis}

Forward osmosis (FO) is a process of extracting sea water from a lower osmotic pressure feed into a higher solution osmotic draw solution across a FO membrane. The FO water can directly desalt sea water as a feed solution by employing higher osmotic pressure draw solution alternatively the FO process can be coupled with and existing RO to create a lower energy desalination technology. As indirect desalination is achieved by the FO which dilutes the sea water going to the RO, FO acts as a pre-treatment of the feed water to the RO reducing the required pressure which in turn reduces the required energy consumption.

\section{b) Membrane distillation}

It works by using thermal gradient, with water vapor transported across a hydrophobic microporous membrane using less temperature and pressure than convention distillation system. The MD process almost uses only 1 bar pressure, MD process is modular and product water quality are insensitive to the feed water salinity up to $200000 \mathrm{ppm}$, which is its greatest advantage over MSF and RO. It is also less prone to fouling than pressure driven membrane process and requires smaller foot print than the current processes. The product water recovery is close $90 \%$ with recirculation of concentrated brine increasing the reflux. MD requires energy input in two forms thermal to drive the separation process and electrical to move the feed, product and brine flows of the system. MD can achieve the targeted $1 \mathrm{kwh} / \mathrm{m}^{3}$ If powered by waste heat to satisfy thermal requirement [23].

\section{c) Nano-filtration/Ultrafiltration}

$\mathrm{NF}$ is playing a vital role in softening the sea water. An integrated membrane system of nanofiltration and ultrafiltration can be used as the pre-treatment for the seawater to increase the overall efficiency of the SWRO plant. Various factors like operating pressure, cross-flow velocity and feed temperature can be examined to increase the effectiveness of the process. With the advancement of nanomaterials more efficient quality of membranes can be produced to maximize the results $[7,24,25]$.

\section{Acknowledgement}

The support of Center for Advanced Materials, Qatar University through grant number QUST-2-CAM-2018-1 is highly acknowledged.

\section{References}

1. Sodoudi S, Shahmohamadi P, Vollack K, Cubasch U, Che-Ani AI (2014) Mitigating the Urban Heat Island Effect in Megacity Tehran. Advances in Meteorology 2014(547974): 19.

2. Li Y, Babcock RW (2014) Green roofs against pollution and climate change. A review. Agronomy for Sustainable Development 34(4): 695705 . 


\section{Civil Engineering Research Journal}

3. Croitoru C, Nastase I, Sandu M, Lungu C (2016) Multi-criteria design and impact on energy consumption of a residential house- a parametric study. Energy Procedia 85(3): 141-148.

4. Lantitsou KI, Panagiotakis GD (2017) Thermal analysis of residencies based on solar design principles -a case study in Thessaloniki, Greece. Fresenius Environmental Bulletin 26(2): 1254-1262.

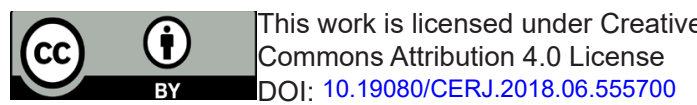

5. Vaccari FP, Gioli B, Toscano P, Perrone C (2013) Carbon dioxide balance assessment of the city of Florence (Italy), and implications for urban planning. Landscape and Urban Planning 120 (2): 138-146.

Track the below URL for one-step submission

https://juniperpublishers.com/online-submission.php

- Swift Peer Review

- Reprints availability

- E-prints Service

- Manuscript Podcast for convenient understanding

- Global attainment for your research

- Manuscript accessibility in different formats

( Pdf, E-pub, Full Text, Audio)

- Unceasing customer service 